\title{
CT PELVIMETRY OF VARIANT PELVIS AND CHILD BIRTH PROGNOSIS
}

Christel Marie Lalèyè ${ }^{1-3}$, Simon A. Azonbakin ${ }^{2}$, Vincent Delmas ${ }^{1}$, Augustin-Karl Agossou-Voyèmè ${ }^{3}$, Richard DOUARD ${ }^{1}$, Gervais Hounnou ${ }^{3}$, Olivier Ami ${ }^{4-5}$.

1. URDIA EA 4465, University of Paris Descartes, France

2. Laboratory of Histology, Reproductive Biology, Cytogenetics and Medical Genetics; University of Abomey-Calavi

3. Laboratory of Anatomy and Organogenesis, University of Abomey-Calavi, Bénin

4. Obstetric Gynecology, Hospital Antoine Béclère, APHP, Clamart

5. Radiology Department, Hospital Antoine Béclère, APHP, Clamart

Correspondance to Christel Marie Laleye email laleyefor@yahoo.fr

\section{ABSTRACT}

The aim of this study was to determine the threshold values of pelvimetry by scanning and to evaluate the ability of the pelvimetry alone to diagnose a fetal-pelvic disproportion. It was an observational retrospective study on 410 pregnant women who had a scanner pelvimetry for any reasons. Based on the fetal presentations, two subgroups (breech and cephalic -others) have been defined. Measurements of the main obstetric diameters (promonto-retropubic, median transverse and dual sciatica) were taken. The 5th and 10th percentile were calculated as well as the 90th and 95th to determine the threshold values of pelvimetry by scanner. The scanner values found on $\mathrm{CT}$ were compared with the standard $X$ ray pelvimetry values. Referring to extreme values obtained by pelvimetry scanner, some pathological pelvic brim were reconstructed in 3D. Moreover, the delivery prognostic was analyzed by crossing the pelvic inlet dimensions (Magnin index) and pelvic outlet dimensions (bi-sciatic diameter) with the outcome of the delivery. The mean values of the scanno-pelvimetry measurement in our series were: $m 12,39 \mathrm{~cm}( \pm 1)$ for the promontoretropubic diameter, $12.88 \mathrm{~cm}( \pm 1.01)$ for the transverse median diameter and $11 \mathrm{~cm}( \pm 1.32)$ for the bi-sciatic diameter. These measurements provided an accuracy less than $1 \mathrm{~cm}$ compared to the standard ray pelvimetry. Although Magnin index at 23 allows a vaginal delivery, $51 \%$ of oursample have failed. Moreover, for the Magnin index at 24 and 25, the vaginal delivery failure rate remains high:45.1\% and $39.61 \%$ respectively. Compared to classical pelvimetry, pelvimetry by scanner provides additional precision and allows to study the geometry of the basin. However, the pelvimetry alone could not be effective to establish the prognosis of vaginal delivery.

Key words: scanno-pelvimetry, prognosis, delivery.

\section{INTRODUCTION}

Dystocia is a major problem in Africa. It is still responsible for several fetal deaths and for the mother, urogenital fistula especially by vesico-vaginal fistulas. Dystocia is predictable by pelvimetry techniques and should be useful in programmed caesareans. Studies conducted by authors like Thoms (1922), Jacobs (1934), Colcher and Sussman (1944), Moir (1947), Trillat and Magnin (1948) brought X-ray pelvimetry into current practice. Main morphological types of female basins were described from those works. Standard radiopelvimetry has been used by obstetricians since 1940 as a method of predicting cephalopelvic disproportion and breech presentation (Rozeberg et al., 2007). It is called the Magnin index in french (sum of the promonto-retro-pubic and transverse median diameters) which is a reference for the $\mathrm{x}$-ray diagnosis of cephalopelvic disproportion. The literature reports conflicting data on the value of radiopelvimetry (Ferguson et al., 1998; Thurnau et al., 1999; Rozenberg et al., 2007). Unlike to the aim of Magnin index which consist to detect fetopelvic disproportions, it does not compare the measurements of the fetal head with those of the maternal pelvis. The purpose of this study is to determine threshold values for pelvic computed tomography 
pelvic disproportion diagnosis.

\section{MATERIALS AND METHOD}

It was a retrospective observational study conducted with respect for the confidentiality of the data. The Ethics Committee indicated that it was unnecessary to have an authorization for this work. It covers a period of 10 years from 1999 to 2009 and focused on 410 pregnant women who had a pelvimetry scanner for different reasons: scar uterus, suspected fetal macrosomia, twin pregnancy, obstetrical history. These 410 scanners were divided into two subgroups: headquarters, head-others. Measurements of the major promonto-retro-pubic (PRP), medial transverse (TM) and bi-isciatic (BS) obstetrical diameters were taken. The $5^{\text {th }}, 10$ th, 90 th and 95th percentiles were calculated to determine threshold values for pelvimetry in slice scanning. The dimensions found on the scanner were compared to standards values in radiopelvimetry. The Magnin index of the cranial perimeter of children at and their

\section{Scanner pelvimetry values}

Table I shows the values of scanner pelvimetry, Magnin index, head circumference, and birth weight for each subgroup. Pelvis with a fetus in seat presentation are only considered normal. Indeed, in practice, pelvimetry for a fetus in cephalic presentation is indicated in case of suspicion of cephalopelvic disproportion. The mean values of the pelvimetry scan in our series were $12.39 \mathrm{~cm}( \pm 1)$ for the promontoretro-pubic diameter, $12.88 \mathrm{~cm}( \pm 1.01)$ for the medial transverse and $11.00 \mathrm{~cm}( \pm 1.03)$ for bi-sciatica.

\section{D reconstruction of pathological pelvis}

Using the median values and when reffered toto the extremes calculated from the 5th, 10th, 90th and 95th percentiles, we have identified in our series some pathological pelvis. Table II shows the measurements of weight were associated to these pelvimetry classical data. When pelvimetry values are abnormal, some pathological pelvis were designed into 3D. Moreover, the outcome of the birth was crossed with the upper strait measurements through the Magnin index and the lower strait measurements through the bisciatic diameter. The Pregnant women aged 32 ( \pm 5.5 years). The average body weight of new born children was $2970 \mathrm{~g}( \pm 564 \mathrm{~g})$. A SIEMENS scanner device 128-strip (2X64) was used. The helical acquisition mode was used. The helical mode is defined by a rotation simultaneous movement of the tube-detector around the patient (rotational movement) and a longitudinal translation movement at a constant speed of the table. The statistics were performed with SPSS software version 16.0.

\section{RESULTS}

the different diameters for these pelvis. Figures 1, 2 and 3 illustrate their volume.

\section{Outcome of deliveries}

The Magnin Index is used to establish the prognosis of delivery. For a Magnin index greater than 22, the prognosis for vaginal delivery is considered favorable (4). Basing on this statement, in our sample, despite Magnin index was $23,35.3 \%$ of emergency cesarean section were recorded. $15.7 \%$ of instrumental extraction were also recorded, all this raised the vaginal delivery to $51 \%$ of delivery failure. Table III presents the overall results of deliveries according to the different values of the Magnin index. The use of bisciatic diameter does not improve the prognosis. Table IV presents the outcome of deliveries according to the bi-sciatic diameter. 


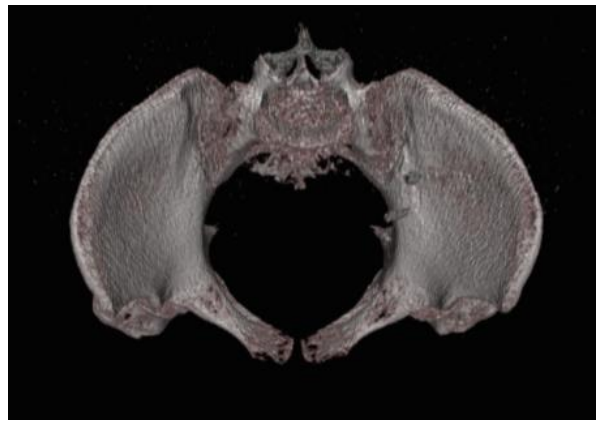

Figure1: Android basin

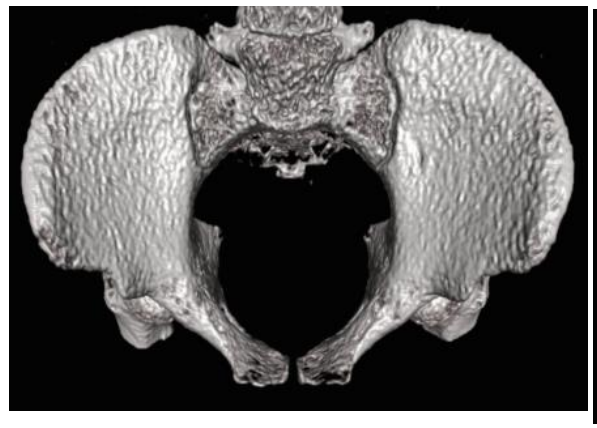

Figure 2: Anthropoid basin and narrowed to thorns

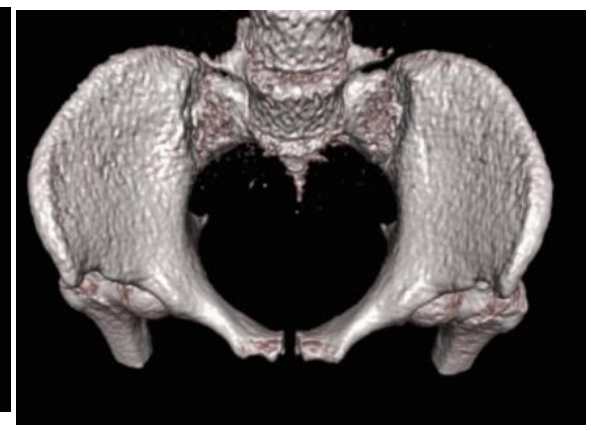

Figure3: A generally shrunk basin

Table 1: Pelvimetry from sectional imaging (CT)

\begin{tabular}{|c|c|c|c|c|}
\hline \multirow{2}{*}{} & \multicolumn{2}{|c|}{ Seat } & \multicolumn{2}{c|}{ Head and other } \\
\cline { 2 - 5 } & Median & $9^{\text {th }}$ percentile & Median & $5^{\text {th }}$ percentile \\
\hline PRP & $12.39( \pm 1)$ & 14.02 & $12.10( \pm 1.04)$ & 14.02 \\
\hline TM & $12.88( \pm 1,01)$ & 14.02 & $12.70( \pm 0.66)$ & 14.00 \\
\hline BS & $11.00( \pm 1,03)$ & 12.81 & $10.95( \pm 1)$ & 12.52 \\
\hline Magnin & $23.98( \pm 1,47)$ & 26.20 & $23.70( \pm 1.37)$ & 26.02 \\
\hline CPatbirth & $35.00( \pm 2,83)$ & 38.00 & $34.50( \pm 1.58)$ & 38.00 \\
\hline Birthweight & $3090( \pm 482,75)$ & 3880 & $2925,00( \pm 564,41)$ & 3768,00 \\
& & & & \\
\hline
\end{tabular}

Table 2: Variant Basins

\begin{tabular}{|l|l|l|l|}
\hline & PRP & TM & BS \\
\hline Normal & 12.39 & 12.88 & 11.00 \\
\hline Android & 15.0 & 11.7 & 11.43 \\
\hline Anthropoid & 12.7 & 11.9 & 8.3 \\
\hline Overall Shrunk & 10.1 & 10.68 & 9.9 \\
\hline
\end{tabular}


Table 3: Birth outcome according to the different values of the Magnin

\begin{tabular}{|c|c|c|c|c|c|c|c|c|}
\hline Magnin & $\begin{array}{c}\text { Scheduled } \\
\text { caesarean } \\
\text { section } \\
(\%)\end{array}$ & $\begin{array}{c}\text { Cesarean } \\
\text { section } \\
\text { urgently }\end{array}$ & $\begin{array}{c}\text { Cesarean } \\
\text { emergency } \\
\text { in relation } \\
\text { to } \\
\text { authorized } \\
\text { low } \\
\text { pathway }\end{array}$ & $\begin{array}{c}\text { Instrumental } \\
\text { extraction }\end{array}$ & $\begin{array}{c}\text { Instrumental } \\
\text { Extraction } \\
\text { Relative to } \\
\text { Authorized } \\
\text { Low } \\
\text { Channels }\end{array}$ & $\begin{array}{c}\text { Low } \\
\text { birth }\end{array}$ & $\begin{array}{c}\text { Low path } \\
\text { failure } \\
\text { rate } \\
\text { compared } \\
\text { to } \\
\text { authorized } \\
\text { low path }\end{array}$ & $\begin{array}{c}\text { Average } \\
\text { birth } \\
\text { weight }\end{array}$ \\
\hline 25 & 24 & $16.92 \%$ & $22.45 \%$ & $9.23 \%$ & $12.24 \%$ & $49.23 \%$ & $34.69 \%$ & $3100 \mathrm{~g}$ \\
\hline 24 & 21 & $27.69 \%$ & $35.3 \%$ & $7.69 \%$ & $9.8 \%$ & $43.08 \%$ & $45.1 \%$ & $2985 \mathrm{~g}$ \\
\hline 23 & 19 & $28.57 \%$ & $35,3 \%$ & $12.70 \%$ & $15.7 \%$ & $39.68 \%$ & $51 \%$ & $3011 \mathrm{~g}$ \\
\hline 22 & 13 & $32.61 \%$ & $37.5 \%$ & $19.57 \%$ & $22.5 \%$ & $34.78 \%$ & $60 \%$ & $2863 \mathrm{~g}$ \\
\hline 21 & 37 & $52.64 \%$ & $83.33 \%$ & $5.26 \%$ & 8.33 & $5.26 \%$ & $91.66 \%$ & $2972 \mathrm{~g}$ \\
\hline 20 & 67 & $8.33 \%$ & $25 \%$ & $16,67 \%$ & $50 \%$ & $8.33 \%$ & $75 \%$ & $3023 \mathrm{~g}$ \\
\hline
\end{tabular}

Table 4: Birth outcome by bi-sciatic diameter

\begin{tabular}{|c|c|c|c|c|c|}
\hline BS & $\begin{array}{c}\text { Scheduled } \\
\text { caesarean } \\
\text { section }\end{array}$ & $\begin{array}{c}\text { Cesarean } \\
\text { section } \\
\text { urgently }\end{array}$ & $\begin{array}{c}\text { Instrumental } \\
\text { extraction }\end{array}$ & Low birth & $\begin{array}{c}\text { Average } \\
\text { birth weight }\end{array}$ \\
\hline 8 & $100 \%$ & O\% & $0 \%$ & $0 \%$ & $3175 \mathrm{~g}$ \\
\hline 9 & $21.57 \%$ & $29.41 \%$ & $17.65 \%$ & $31.37 \%$ & $2942 \mathrm{~g}$ \\
\hline 10 & $17.35 \%$ & $25.51 \%$ & $12.24 \%$ & $41.90 \%$ & $3023 \mathrm{~g}$ \\
\hline 11 & $22.86 \%$ & $31.43 \%$ & $10.47 \%$ & $35.24 \%$ & $3001 \mathrm{~g}$ \\
\hline 12 & $37.21 \%$ & $16.28 \%$ & $4.65 \%$ & $41.86 \%$ & $2984 \mathrm{~g}$ \\
\hline 13 & $14.29 \%$ & $28.57 \%$ & $0 \%$ & $57.14 \%$ & $3047 \mathrm{~g}$ \\
\hline
\end{tabular}

\section{DISCUSSION}

This study defined the median pelvis size in a normal population for which pelvimetry was performed for some other reason than an abnormal clinical examination. Little such data are available in the literature on normal pelvis (Morgan et al., 1992; Impey et al., 1998; Ikhena et al., 1999). This study proposed with acceptable accuracy, median values for interpretation in pelvimetry scan. Beyond the medians, the 10th, 90th,5th and 95th percentiles provide reference scanning values for radiologists. In the group of normal pelvis, the 10th and 90th percentiles were quite close to the median measures with a gap a centimeter order. These data indicate that pelvis measurements in the human species are relatively well conserved and consistent with standard cephalic size delivery (biparietal diameter estimated at $9.6 \mathrm{~cm}$ for normal) (Salk et al., 2015). In the group of pathological pelvis the median values of different diameters were too low, as well as the foetus: cranial perimeter of $34.50 \mathrm{~cm}$ against $35 \mathrm{~cm}$ in the normal pelvis and an average weight of $2925 \mathrm{~g}$ against $3090 \mathrm{~g}$. The difference between the normal median values and the previous radiological reference is approximatively $1 \mathrm{~cm}$. Standard references available possessed no certainty when transposed into pelvimetry scanner (Van Look et al., 1997). The soft of x-ray could lead to bad interpretation since the doctor couldn't know, for example, whether an edge is in front or behind the plane.

In addition, the $\mathrm{x}$-ray quality also depends on the geometry of the patient and the installation, which may not always be calibrated in the same way from one device to another. The purpose of pelvimetry is to predict the vaginal delivery. The aim is to reduce the number of unnecessary cesarean sections while improving perinatal care (Korhonen et al., 2014; Korhonen et al., 2015). A wayto achieve this is by calculating 
the Magnin Index (PRP + TM). The usefulness of this index is currently controversial (Korhonen et al., 2014; Korhonen et al., 2015). The perception of the outcome of the birth with the value of the Magnin index allows us to criticize this index. Cesarean emergencies and instrumental extractions highlighted the failure of the vaginal approach with a greater risk of neonatal morbidity. Scheduled caesareans were not usefull to analyze Magnin's index because we could not presume in these patients the good course of vaginal delivery. On the other hand, the failure rate of the low path is a better indicator of the effectiveness of the Magnin index. For a Magnin value of 23, for which vaginal delivery is acceptable, the failure rate was about $51 \%$. That means, more than half of women with normal Magnin Index could not deliver by vaginal way without risk. Moreover, for higher Magnin Index values of 24 and 25 the low path failure rate remains high at $45.1 \%$ and $39.61 \%$, respectively. The Magnin index only explores the upper strait. The lower strait is also involved in the genesis of dystocic deliveries. From measurements of the bi-sciatic diameter (inferior strait), it is found that, as for the Magnin index, the percentage of emergency deliveries and instrumental extractions increase appreciably with the decrease of the bi-sciatic diameter. This obey to the law of proportion of the human body which allows a ratio of proportionality between the different measurements of the human body. Moreover, promonto-retro-pubic and transverse medial diameters correspond to a large bi-sciatic diameter. Analysis of our data led us to the conclusion that pelvimetry alone did not provide a good prediction of mechanical dystocia. The scanner pelvimetry has the advantage to provide continuously data on the global geometry of the pelvis and to allow reconstruction in 3D. During delivery, the size of the pelvis useful, but its geometry and that of the fetal head would be more important. One would thus obtain a better prediction by confronting the pelvis with the fetal head. Instead of proposing a pelvimetry score, we would propose a cephalopelvic confrontation score. This may reduce the number of unnecessary procedures and improve scheduling of caesareans.

In conclusion, pelvimetry scan provides additional precision compared to conventional radiopelvimetry and allows the study of pelvis geometry. We have shown that pelvimetry alone can not be effective in preventing mechanical dystocia. This opens up prospects for improving the prediction of cephalopelvic confrontation by the use of new techniques. Pelvimetry projection still has good days in front of it and needs to be evaluated constantly with the appearance of new tools that are implemented in medical imaging.

\section{REFERENCES}

1. Rozenberg P. 2007. Quelle place pour la radiopelvimétrie au XXIe siècle? Gynécologie Obstétrique Fertil.,35(1):6-12.

2. Thurnau GR, Scates DH, Morgan MA. 1999. The fetal-pelvic index: A method of identifyingfetal-pelvic disproportion in womenattempting vaginal birthafterpreviouscesareandelivery. Am J ObstetGynecol.,165(2): 353-8.

3. Ferguson II Je, Newberry YG, Deangelis GA, Finnerty JJ, Agarwal S, Turkheimer E 1998. The fetal-pelvic index has minimal utility in predictingfetal-pelvic disproportion. Am J ObstetGynecol.,79(5):1186-92.

4. Fremondiere P, Fournie A. 2011. Disproportion fœto-pelvienne et radiopelvimétrie. Gynécologie Obstétrique Fertil.,39(1):8-11.

5. Buthiau D. 2003. La pelvimétrie par scanner: récentes évolutionsComputerizedtomographypelvimetry: recent advances. Gynécologie Obstétrique Fertil.,31(5):465-70. 
6. Morgan MA, Thurnau GR. 1992. Efficacy of the fetal-pelvic index in nulliparouswomenathighrisk for fetal-pelvic disproportion. Am J ObstetGynecol.,166(3):810-4.

7. Impey L, O'herlihy C. 1998. First deliveryaftercesareandelivery for strictlydefinedcephalopelvic disproportion. ObstetGynecol.,92 (5): 799-803.

8. Ikhena SE, Halligan AW, Naftalin JS. 1999. Has pelvimetry a role in currentobstetric practice? J ObstetGynaecol.,19 (5): 463-5.

9. Salk I, Cetin M, Salks, Cetin A. 2015. Determination of Frequency of Gynecoid Pelvis by Three-dimensionalComputedTomography in Non-pregnantMultiparousWomen. Med PrincPractInt J Kuwait Univ Health Sci Cent. 25: 40 - 48.

10. Van Loon AJ, Mantingh A, Serlier EK, Kroon G, Mooyaart EL, Huisjes HJ. 1997. Randomisedcontrolled trial of magnetic-resonancepelvimetry in breechpresentationpatterm. The Lancet. 350:1799-804.

11. Korhonen $U$, Taipale P, Heinonen S. 2015. Fetal-pelvic index to predictcephalopelvic disproportion - a retrospectiveclinicalcohortstudy. Acta Obstet Gynecol Scand. 94:615-21.

12. Korhonen $U$, Taipale $P$, Heinonen S. 2014. The diagnostic accuracy of pelvicmeasurements: threshold values and fetal size. ArchGynecolObstet. 290:643-8. 